\title{
Prevention of In Vitro Neutrophil-Endothelial Attachment through Shedding of L-Selectin by Nonsteroidal Antiinflammatory Drugs
}

\author{
Federico Díaz-González, “ Isidoro González-Alvaro, * Miguel R. Campanero, Faustino Mollinedo," Miguel A. del Pozo, \\ Cecilia Muñoz, Juan P. Pivel, and Francisco Sánchez-Madrid \\ Sections of *Rheumatology and Immunology, Hospital de la Princesa, Universidad Autónoma de Madrid, 28006, Madrid, Spain; and
}

${ }^{\ddagger}$ Centro de Investigaciones Biológicas (CSIC), 28006 Madrid, Spain

\begin{abstract}
The activation of the endothelial cells by extravascular stimuli is the key event in the extravasation of circulating leukocytes to target tissues. L-selectin, a member of the selectin family, is constitutively expressed by white cells, and is the molecule involved in the initial binding of leukocytes to activated endothelium. After activation, leukocytes rapidly release L-selectin from the cell surface, suggesting that the functional activity of this molecule is controlled in large part by its appearance and disappearance from cell surface. We have studied in a neutrophil-activated endothelial cell binding assay, the effect of different antiinflammatory drugs (steroidal and nonsteroidal) in the L-selectin-mediated interaction of neutrophils with activated endothelial cells. Some nonsteroidal antiinflammatory drugs (NSAIDs), such as indomethacin, diclofenac, ketoprofen, and aspirin, but not steroids, strongly inhibited the neutrophil-endothelial cell attachment. Furthermore, we also investigated the underlying mechanism of this functional effect. The expression of $L$-selectin on the neutrophil surface rapidly decreased in the presence of different NSAIDs, in a dose- and timedependent manner, whereas no changes in the expression of other adhesion molecules such as CD11a, CD11b, CD31, or ICAM-3 (CD50) were observed. Interestingly, studies in vivo on healthy volunteers treated with physiological doses of indomethacin showed a significant decrease of $\mathbf{L}$-selectin neutrophil expression. Only diclofenac induced an upregulation of CD11b expression, suggesting an activating effect on neutrophils. No enzyme release was observed upon treatment of neutrophils with different NSAIDs, indicating a lack of degranulatory activity of NSAIDs, with the exception of diclofenac. The downregulation of $L$-selectin expression was due to the rapid cleavage and shedding of the membrane L-selectin, as determined by both immunoprecipitation from ${ }^{125} \mathrm{I}$-labeled neutrophils, and quantitative estimation in cell-free supernatants. These results suggest that NSAIDs exert a specific action on adhesion receptor expression in neutrophils, which might account, at least in part, for the antiinfiammatory activities of NSAIDs. (J. Clin. Invest. 1995.
\end{abstract}

Address correspondence to Francisco Sánchez-Madrid, Servicio de Inmunología, Hospital de la Princesa, c/Diego de León, 62, 28006 Madrid, Spain. Phone: 34-1-4023347; FAX: 34-1-3092496.

Received for publication 29 June 1994 and in revised form 16 November 1994.

J. Clin. Invest.

(C) The American Society for Clinical Investigation, Inc.

$0021-9738 / 95 / 04 / 1756 / 10 \quad \$ 2.00$

Volume 95, April 1995, 1756-1765
95:1756-1765.) Key words: adhesion molecules $•$ L-selectin - neutrophils • nonsteroidal antiinflammatory drugs

\section{Introduction}

The aim of the inflammatory response is to eliminate deleterious agents and repair the damaged tissue. When the inflammation is persistent, it may be injurious to the host, causing severe tissue destruction and dysfunction as occurs in the joints of rheumatoid arthritis patients. The control of inflammation in human diseases characterized by an abnormal chronic inflammatory response is one of the challenges of the present medicine.

Leukocyte extravasation is essential in the inflammatory response. This process can be divided into three steps: initial interaction of leukocytes with activated endothelium (rolling), leukocyte activation with firm adhesion to endothelial cells and, finally, their extravasation into the surrounding tissues $(1,2)$. Several adhesion molecules are involved in the processes of adhesion and migration of leukocytes through vascular endothelium at sites of inflammation (1-3). Among them, L-selectin (Leu-8, LAM-1, MEL 14, or LECAM-1) has a key role in the initial attachment of circulating leukocytes to endothelium. This molecule is responsible for the rolling of leukocytes along the vascular walls, as a prerequisite to arrest movement and firm adhesion, thus allowing the interaction of other molecules (integrins) which account for trans-endothelial migration and cell extravasation to the target tissues (3-6).

L-selectin is a member of the selectin family of adhesion molecules that mediate adhesive interactions among endothelium, leukocytes, and platelets (7-9). Three members of the selectin family have been described which are differentially expressed $(7,8)$. P-selectin (CD62) is constitutively present in granules of platelets and endothelial cells and is rapidly translocated to the surface after specific stimuli $(10-12)$. E-selectin (ELAM-1) is restricted to endothelial cells and is expressed after stimulation with certain cytokines (13). E-selectin and Pselectin mediate endothelial interactions with neutrophils, monocytes, and some lymphocytes $(7,8)$. L-selectin is a highly glycosylated protein of 95-105 kD on neutrophils and $74 \mathrm{kD}$ on lymphocytes that is constitutively expressed by most of leukocytes $(14,15)$. This adhesion molecule is involved in leukocyte-endothelial cell interactions by recognition of carbohydrate determinants found in several endothelial cell ligands, including GlyCAM-1 (16), CD34 (17), MAdCAM-1 (18) and $P$ - and E-selectins (19). Interestingly, L-selectin is rapidly shed after neutrophil activation both in vitro $(20-22)$ and in vivo $(23,24)$. A soluble form of L-selectin that retains functional activity has been detected in sera from normal human donors (25). In this regard, we have also described a soluble form of L-selectin in synovial fluid from different inflammatory joint diseases (24). 
Nonsteroidal antiinflammatory drugs (NSAIDs) ${ }^{1}$ are a heterogeneous group of chemical compounds very commonly prescribed for the control of inflammatory human diseases (26). The precise mechanism of action of NSAIDs is not completely understood. It has been proposed that the major mechanism of action of these drugs is the inhibition of prostaglandin synthesis (27). However, this inhibitory activity does not account for all antiinflammatory effects of NSAIDs. Additional effects of NSAIDs have been described $(28,29)$, but none of them explain the entire spectrum of their antiinflammatory activities.

To search for functional and molecular targets of NSAIDs, we examined the possible effect of different antiinflammatory drugs (steroidal and nonsteroidal) at the first step of neutrophil extravasation, the L-selectin-mediated interaction of neutrophils with activated endothelial cells. We found that most NSAIDs, but not steroids, strongly inhibited this event. Furthermore, we also investigated the mechanism underlying this functional effect, and we found that it is due to the loss of L-selectin expression in neutrophils through a shedding mechanism.

\section{Methods}

Antibodies and reagents. The following mAbs were used: Bear-1 antiCD11b, D3/9 anti-CD45, TP1/40 anti-CD11a, HP2/19 anti-ICAM-3, TP1/15 anti-CD31, and P3X63 myeloma culture supernatant as a negative control $(30,31)$. The Leu-8 anti-L-selectin $\mathrm{mAb}$. was purchased from Becton Dickinson Immunocytometry Systems (Mountain View, CA). LAM1-3 and LAM1-12 anti-L-selectin mAbs (32) were kindly provided by Dr. T. Tedder (Duke University, Durham, NC).

TNF- $\alpha$ (sp act $3.2 \times 10^{7} \mathrm{U} / \mathrm{mg}$ ) was purchased from Wichem International (Vienna, Austria). Aspirin, indomethacin, diclofenac, ketoprofen, piroxicam, dexamethasone, and PMA, were purchased from Sigma Chemical Co. (St. Louis, MO).

Isolation and treatment of neutrophils. Neutrophils were isolated from peripheral blood by Ficoll-Hypaque density gradient centrifugation (Pharmacia Diagnostics AB, Uppsala, Sweden), followed by sedimentation at $1 \mathrm{~g}$ in $1.3 \%$ dextran (Sigma Chemical Co.) at room temperature. The neutrophil-enriched fraction was further purified by hypotonic lysis of erythrocytes, giving a purity $>98 \%$. The cells were resuspended on Hepes-glucose buffer (glucose $150 \mathrm{mM} \mathrm{NaCl}, 5 \mathrm{mM} \mathrm{KOH}, 10$ $\mathrm{mM}$ Hepes, $1.2 \mathrm{mM} \mathrm{MgCl}, 1.3 \mathrm{mM} \mathrm{CaCl}, 5.5 \mathrm{mM}, \mathrm{pH}: 7.5)$. The experiments were carried out in $15 \mathrm{ml}$ disposable polypropylene tubes (Falcon Labware, Oxnard, CA).

Neutrophils were incubated in Hepes-glucose buffer with the different drugs, TNF- $\alpha$ or PMA at times and temperatures indicated. In some assays, $4 \mathrm{~g} /$ liter of HSA was included in the buffer. The dose of each drug was chosen according to their potency of antiinflammatory activity. The $\mathrm{pH}$ of the aspirin solution ranged between 6.3 and 7.2, depending on drug concentrations $(1-0.125 \mathrm{mg} / \mathrm{ml})$. These $\mathrm{pH}$ values did not alter the L-selectin neutrophil surface expression. Cell viability, estimated after each treatment by trypan blue exclusion, was $>95 \%$.

Flow cytometry analysis. Flow cytometry analysis was performed in a FACScan ${ }^{\circledR}$ cytofluorometer (Becton Dickinson Immunocytometry Systems). Resting and stimulated neutrophils were incubated with hybridoma culture supernatants followed by washing and labeling with an FITC-labeled goat anti-mouse Ig (Dakopatts, Slastrup, Denmark). Linear and logarithmic immunofluorescence values were obtained in each experiment and the fluorescence produced by the myeloma P3X63 supernatant was considered as background. A total of 5,000 cells was analyzed from each sample adjusting the fluorescence gain so that $~ 5 \%$

1. Abbreviations used in this paper: FI, fluorescence intensity; HUVEC human umbilical vein endothelial cells; MFI, mean FI; NSAIDs, nonsteroidal antiinflammatory drugs. of the cells of the sample with greatest fluorescence were positive in the highest fluorescence channel. The results are displayed either in a linear or logarithmic scale of fluorescence intensity and presented in some figures as the percentage of variation of baseline mean fluorescence intensity (MFI) (\% $\%$ MFI) of total cells.

$\% \Delta \mathrm{MFI}=\left[\left(\right.\right.$ absolute $\mathrm{MFI}_{\text {NSADs }} /$ absolute $\left.\left.\mathrm{MFI}_{\text {medium }}\right)-1\right] \times 100$.

Radiolabeling, immunoprecipitation, and electrophoresis. Cell surface proteins of $6 \times 10^{7}$ neutrophils from a healthy donor were radiolabeled with $\mathrm{Na}^{125} \mathrm{I}$ in a solution with chloroglycoluril (lodo-Gen; Pierce Chemical Co., Rockford, IL), washed twice with PBS and, finally, resuspended on Hepes-glucose buffer with $1 \%$ BSA. Radioiodinated cells were either incubated with NSAIDs or maintained with buffer during $15 \mathrm{~min}$ at $37^{\circ} \mathrm{C}$. The cells and the cell-free supernatants were separated by centrifugation. The cell-free supernatants were supplemented with $1 \mathrm{mM}$ PMSF and $1 \%$ Triton X-100. Cell pellets were lysed with PBS containing $1 \%$ Triton X-100,1\% hemoglobin, and $1 \mathrm{mM}$ PMSF. After overnight dialysis against PBS, samples were precleared with protein A from Staphylococcus aureus coupled to Sepharose. For immunoprecipitation, an equal amount of radioactivity of each sample was mixed with $100 \mu \mathrm{l}$ of $\mathrm{mAb}$ containing hybridoma culture supernatant. Immune complexes were isolated by the addition of $100 \mu \mathrm{l}$ of the 187.1 rat anti-mouse $\kappa$-chain monoclonal antibody, followed by $30 \mu 1$ of protein A coupled to Sepharose. Immunoprecipitates were processed as previously described (33), and samples were subjected to $10 \%$ SDSPAGE and autoradiography with enhancing screens. A prestained molecular weight standard mixture (Sigma Chemical Co.) was used as molecular weight markers.

Neutrophil-endothelial cell attachment assay. Human umbilical vein endothelial cells (HUVEC) were isolated and grown in M199 culture medium supplemented with $10 \%$ FCS, endothelial cell growth factor ( $50 \mu \mathrm{g} / \mathrm{ml}$, Biochemical Technologies Inc., Stoughton, MA) and porcine intestinal heparin ( $50 \mu \mathrm{g} / \mathrm{ml}$, Sigma Chemical Co.) as described (34). Endothelial cells (passage 2-3) were grown to confluence on gelatin $(0.1 \%)$-precoated 24-well plates and stimulated with either TNF$\alpha(20 \mathrm{ng} / \mathrm{ml})$ or medium alone at $37^{\circ} \mathrm{C}$. Cell monolayers were carefully washed and incubated at $4^{\circ} \mathrm{C}$ for 15 min with $200 \mu \mathrm{l}$ of RPMI 1640 medium containing $10 \%$ FCS. Then, $1 \times 10^{6}$ neutrophils in $100 \mu \mathrm{l}$ were added. Previously, neutrophils were incubated with different NSAIDs for the time and dose indicated. Samples of untreated neutrophils were additionally incubated with the anti-L-selectin LAM-1-3 and LAM-1-12 mAbs for $15 \mathrm{~min}$ at $4^{\circ} \mathrm{C}$. After $30 \mathrm{~min}$ of incubation at $4^{\circ} \mathrm{C}$ with rotation at $64 \mathrm{rpm}$, wells were washed $(5 \times)$ with cold PBS and fixed in $1 \%$ of glutaraldehyde in PBS.

The number of bound neutrophils was determined by direct counting on an inverted microscope. Inhibition of neutrophil adhesion was calculated using the level of attachment to unstimulated HUVEC as the baseline, and the level of neutrophils attachment to TNF- $\alpha$-stimulated HUVEC as the maximal value.

Enzymatic activity in supernatants from NSAIDs-treated neutrophils. Resting neutrophils were resuspended at $5 \times 10^{6} \mathrm{cells} / \mathrm{ml}$ in 1 $\mathrm{ml}$ of Hepes-glucose buffer and incubated in the presence of distinct agents for $15 \mathrm{~min}$ at $37^{\circ} \mathrm{C}$. Then, cells were pelleted by centrifugation and supernatants were assayed for marker activities. Enzyme release was determined as the percentage of total enzyme units in the supernatant. Gelatinase, lysozyme, and $N$-Acetyl- $\beta$-glucosaminidase were assayed as described $(30,35)$.

sL-selectin ELISA. The ELISA used to quantitate sL-selectin in the supernatant of NSAIDs-treated neutrophils was generously provided by Bender MedSystem (Vienna, Austria).

Studies in vivo of L-selectin neutrophil expression. Neutrophils from seven healthy volunteers taking per os indomethacin at $25 \mathrm{mg}$, three times a day, were analyzed for cell surface expression of different adhesion molecules by flow cytometry. Peripheral blood samples were obtained just before starting indomethacin $(t=0)$, and 60-90 min after the ingestion of the third $(t=24 \mathrm{~h})$ and sixth doses $(t=48 \mathrm{~h})$. To minimize the daily variations of fluorescence staining and FACScan sensitivity, the fluorescence intensity (FI) corresponding to CD11b and 

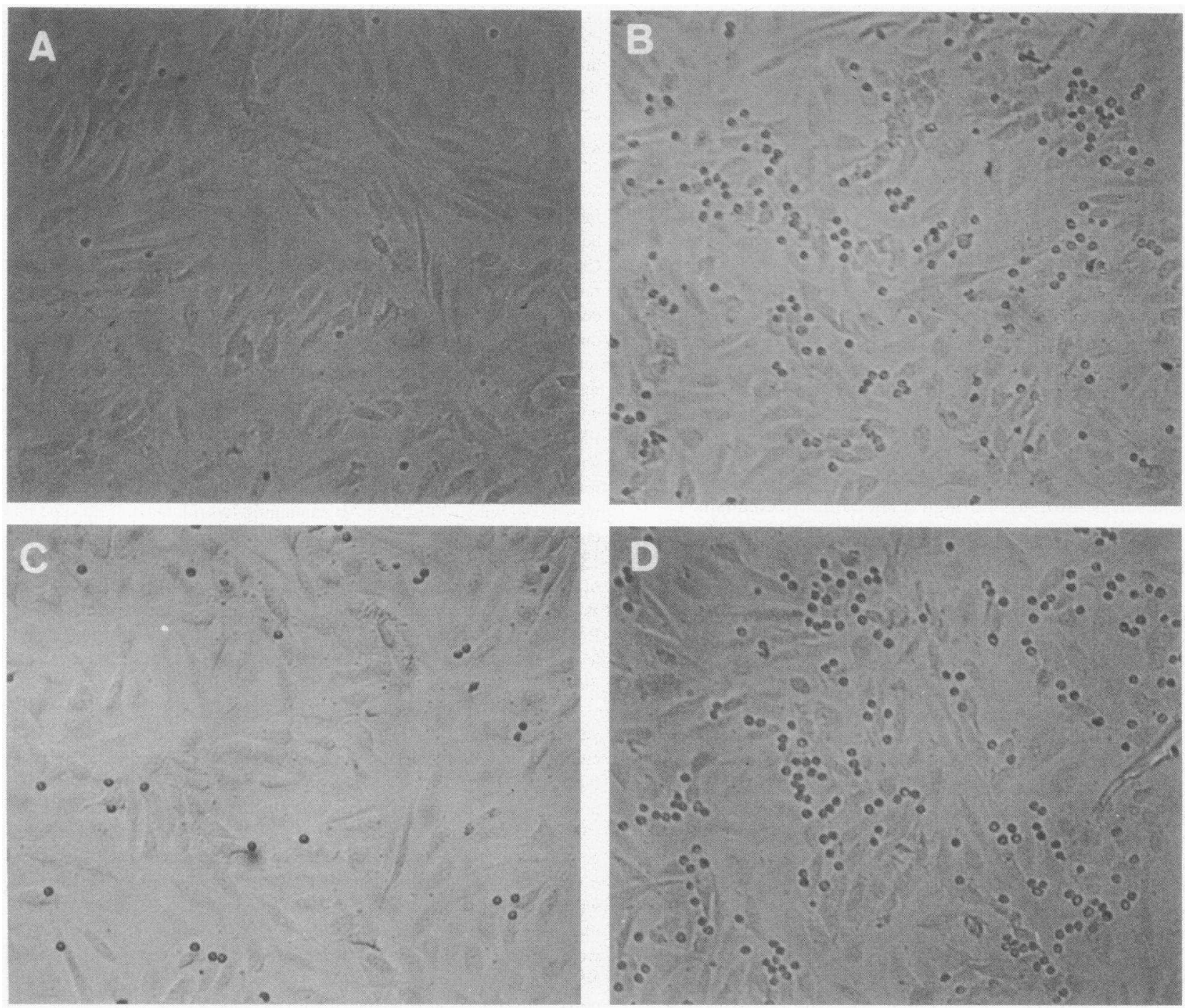

Figure 1. Effect of various antiinflammatory drugs on neutrophil attachment to human endothelial cell monolayers. Confluent endothelial cell monolayers cultured for $6 \mathrm{~h}$ in the presence of $20 \mathrm{ng} / \mathrm{ml} \mathrm{TNF}-\alpha$ were used for neutrophil adhesion assays. A significant adhesion of neutrophils was evident to the activated endothelium $(B)$ (baseline adhesion), but not to unstimulated cell monolayers $(A)$. Preincubation of neutrophils with anti-LAM1-3 significantly decreased the basal adhesion $(C)$. In contrast, the anti-LAM1-12 did not show a significant effect in the neutrophilendothelial attachment assay $(D)$. The adhesion to activated endotelium was nearly completely abrogated by preincubating the neutrophils with indomethacin $(0.2 \mathrm{mg} / \mathrm{ml})(E)$ and diclofenac $(0.2 \mathrm{mg} / \mathrm{ml})(F)$, whereas the adhesion of piroxicam $(0.2 \mathrm{mg} / \mathrm{ml})$ pretreated neutrophils $(G)$ was found similar to control $(B)$.

L-selectin expression in each sample was related to that of CD11a, whose expression remains stable during neutrophil activation and NSAIDs treatment. The results are presented as relative fluorescence intensity (RFI).

$$
\begin{aligned}
\mathrm{RFI}= & (\mathrm{CD} 11 \mathrm{~b} \text { or L-selectin FI }-\mathrm{P} 3 \mathrm{X} 63 \mathrm{FI}) \\
& \times 100 /(\mathrm{CD} 11 \mathrm{a} \mathrm{FI}-\mathrm{P} 3 \mathrm{X} 63 \mathrm{FI}) .
\end{aligned}
$$

Student's $t$ test for paired samples was used to compare the results.

\section{Results}

Inhibition of L-selectin-mediated neutrophil adhesion to endothelial cells by NSAIDs. To study the initial event of inflammation, we analyzed in vitro the binding of neutrophils to HUVEC under nonstatic conditions. In a first step, we studied the effect of the endothelial activation state on the neutrophil attachment. Only few neutrophils were able to bind to unstimulated endothelium (Fig. $1 A$ ). However, when the endothelium was activated with TNF- $\alpha$ to induce the expression of the L-selectin ligand ( $s$ ), a significant number of neutrophils attached to endothelial cells (Fig. $1 B$ ). In agreement with results previously reported by other authors (36), this binding was preferentially mediated by the L-selectin, since anti-L-selectin LAM1-3 mAb reduced $70 \%$ in this interaction (Fig. $1 C$ ). On the other hand, the anti-L-selectin LAM 1-12 mAb did not inhibit the neutrophil-endothelial cell interaction (Fig. $1 D$ ).

Next, we assayed the effect of different antiinflammatory drugs (nonsteroidal and steroidal) on the L-selectin-mediated neutrophil-endothelial interaction. The concentration of each drug tested was proportional to their antiinflammatory potency. When neutrophils were preincubated for $15 \mathrm{~min}$ at $37^{\circ} \mathrm{C}$ either 

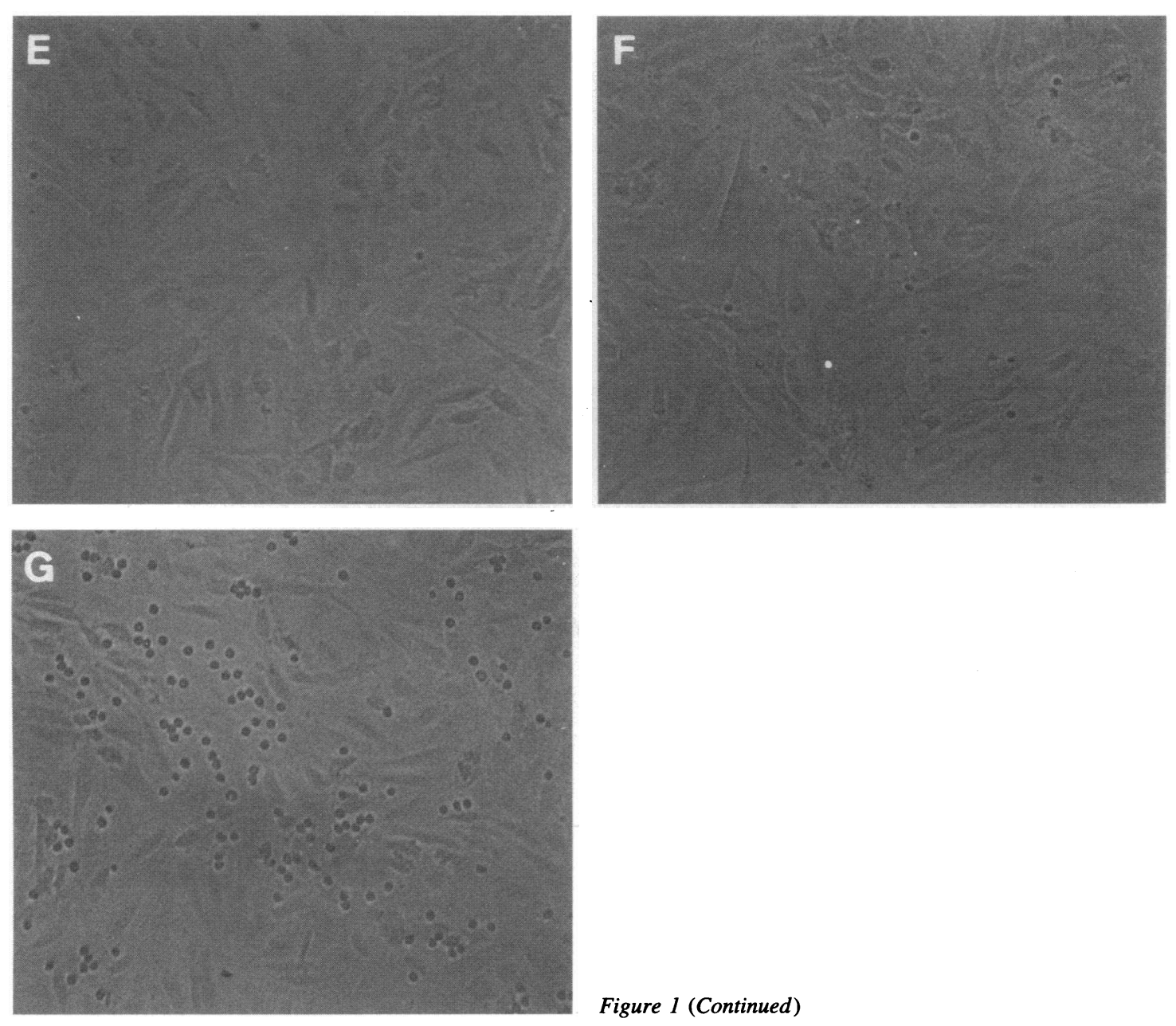

Figure 1 (Continued)

with indomethacin $(0.2 \mathrm{mg} / \mathrm{ml})$, diclofenac $(0.2 \mathrm{mg} / \mathrm{ml})$, or aspirin $(1 \mathrm{mg} / \mathrm{ml})$, the adhesion of neutrophils to endothelium was almost completely inhibited (Fig. $1, E$ and $F$, data not shown). Inhibitory effects were also observed at lower doses, in the range of $10-50 \mu \mathrm{g} / \mathrm{ml}$ for diclofenac or indomethacin, and $0.3 \mathrm{mg} / \mathrm{ml}$ for aspirin. Similar results were obtained when neutrophils were treated with drugs in the presence of physiologic concentrations ( $4 \mathrm{~g} /$ liter) of human serum albumin. Under these conditions, slightly higher drug concentrations were required (not shown). In contrast, piroxicam $(0.2 \mathrm{mg} / \mathrm{ml})$ and dexamethasone $(0.2 \mathrm{mg} / \mathrm{ml})$ did not inhibit the neutrophil adhesion to endothelial cells (Fig. $1 G$, data not shown).

L-Selectin neutrophil expression is downregulated by NSAIDs. To determine the mechanism of inhibition of neutrophil-endothelial cell interaction by NSAIDs, we have studied the possible effect of these drugs on the cell surface expression of L-selectin. Flow cytometry analysis of neutrophils treated with indomethacin, diclofenac, piroxicam, ketoprofen, and aspirin in the same conditions than the adhesion experiments, showed that the cell surface expression of L-selectin was downregulated by all NSAIDs except piroxicam (Fig. 2). Diclofenac and indomethacin showed a stronger effect than ketoprofen and aspirin on L-selectin downregulation (Fig. 2). In contrast, dexamethasone, a potent synthetic steroid, and hydrocortisone, the main physiologic glucocorticoid, did not modify L-selectin expression at concentrations as high as $0.2 \mathrm{mg} / \mathrm{ml}$ (Fig. 2, and data not shown). When these experiments were performed at $4^{\circ} \mathrm{C}$, no modification of the basal expression of L-selectin was observed (data not shown).

The effect of NSAIDs on L-selectin expression on neutrophils was both dose- and time-dependent. Fig. $3 A$ shows a dose-response experiment in which in a decreasing order of potency, diclofenac, indomethacin, and aspirin were effective on the downregulation of L-selectin expression, while piroxicam caused no effect. L-selectin downregulation required slightly higher drug concentrations when assays were performed in the presence of human serum albumin. Under these conditions, doses $>50 \mu \mathrm{g} / \mathrm{ml}$ of diclofenac or indomethacin, and 0.3 $\mathrm{mg} / \mathrm{ml}$ of aspirin were required to induce the effect. Kinetics studies using $40 \mu \mathrm{g} / \mathrm{ml}$ of diclofenac, indomethacin, and piroxicam and $0.5 \mathrm{mg} / \mathrm{ml}$ of aspirin, indicated that diclofenac has the fastest effect by decreasing the L-selectin expression after 5 min of treatment (Fig. $3 \mathrm{~B}$ ). Indomethacin was also active at this concentration, but 60 min were required for displaying a significant effect. Aspirin only had a mild action and piroxicam did not modify the basal expression of L-selectin by periods of time as long as $120 \mathrm{~min}$ (Fig. $3 \mathrm{~B}$ ).

The expression of other cell adhesion molecules, constitutively expressed by neutrophils, such as CD31 (PECAM-1), CD50 (ICAM-3), and CD45, was not altered upon exposure to the different NSAIDs studied. A representative experiment of the effect of indomethacin $\left(0.2 \mathrm{mg} / \mathrm{ml}\right.$ at $37^{\circ} \mathrm{C}$ during 15 

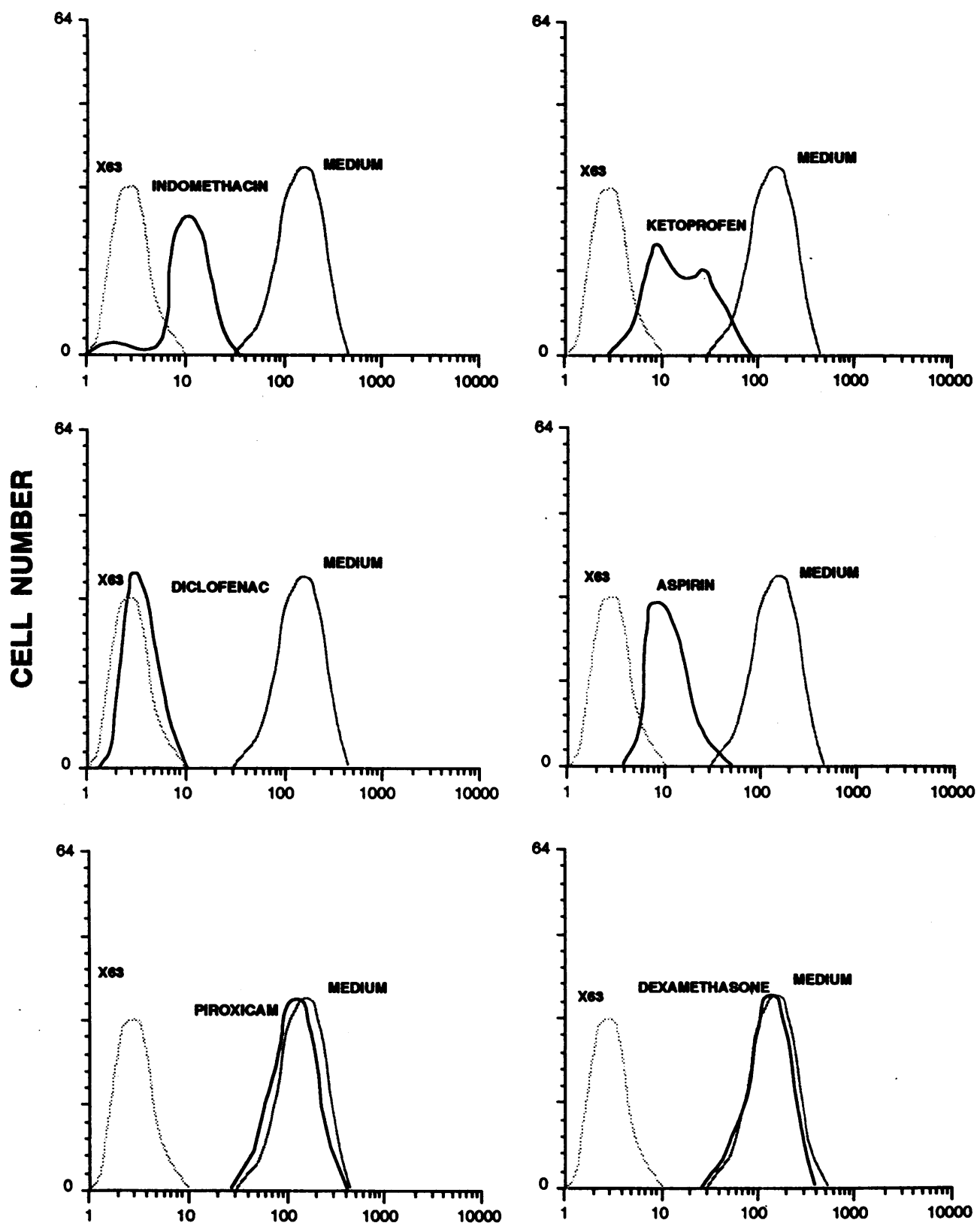

Figure 2. Effect of antiinflammatory drugs on cell surface expression of L-selectin by human neutrophils. Neutrophils were incubated for $15 \mathrm{~min}$ at $37^{\circ} \mathrm{C}$ in medium alone or in the presence of $0.2 \mathrm{mg} / \mathrm{ml}$ indomethacin, diclofenac, and piroxicam, $1 \mathrm{mg} / \mathrm{ml}$ aspirin, $2 \mathrm{mg} / \mathrm{ml}$ ketoprofen, and 0.2 $\mathrm{mg} / \mathrm{ml}$ dexamethasone (solid line). In each histogram is also displayed the basal expression of the L-selectin (medium) and the negative control of immunostaining ( $\mathrm{P} 3 \mathrm{X63}$ ). One representative experiment $(n=5)$ is shown.

min) on the expression of L-selectin, ICAM-3, CD31, and CD45 on neutrophils is shown in Fig. 4.

These data indicate that some NSAIDs induce a downregulation of L-selectin expression on neutrophils, that occurs in a time- and dose-dependent manner.

Effect of NSAIDs on neutrophil activation. L-selectin is rapidly downregulated from the neutrophil cell surface upon cell activation (20-22). Therefore, we analyzed the possibility that NSAIDs could induce neutrophil activation. It has previously been shown that the expression of CD11b and CD45 is upregulated upon neutrophil activation $(30,37)$. The results shown in Fig. 5 A clearly indicate that most of NSAIDs tested did not modify CD11b baseline expression upon $15 \mathrm{~min}$ of cell treatment. However, diclofenac increased CD11b cell surface expression. The expression of CD11a, that is not affected by cell activation, was used as control (Fig. $5 \mathrm{~A}$ ). Kinetics experiments clearly showed that diclofenac, but not indomethacin, piroxicam, or aspirin, clearly enhanced CD11b cell surface expression in a time- and dose-dependent manner (Fig. 5, $B$ and $C$, respectively).

Parallel experiments were conducted to examine the degree of degranulation of the different types of intracellular granules described in human neutrophils $(30,35)$. As shown in Table I, neither gelatinase (a marker for tertiary granules) nor lysozyme (a marker for specific granules) were secreted upon cell preincubation with different NSAIDs, with the exception of diclofenac. TNF- $\alpha$ and diclofenac induced a significant release of gelatinase and a slight release of lysozyme. As these agents augmented the cell surface expression of CD11b (Fig. 5), these data further support the location of this antigen in gelatinase- 
A

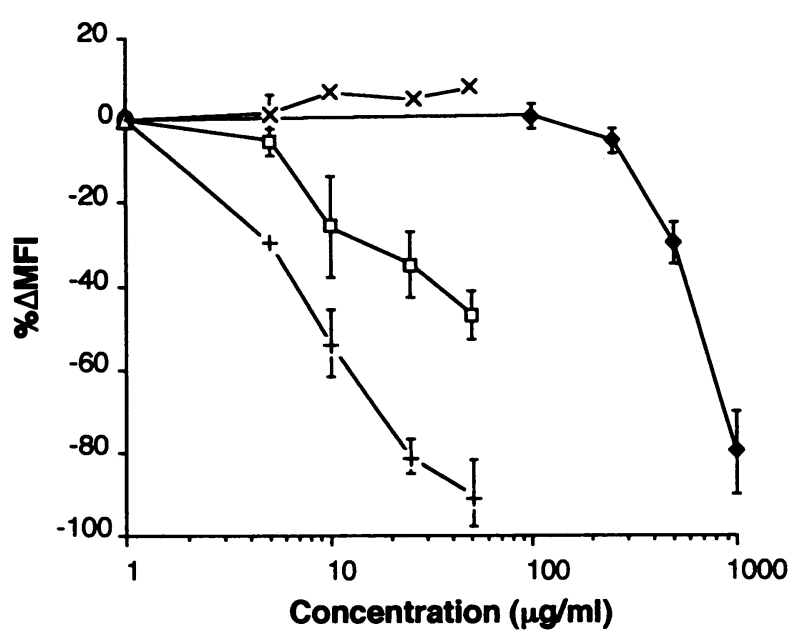

$\mathbf{B}$

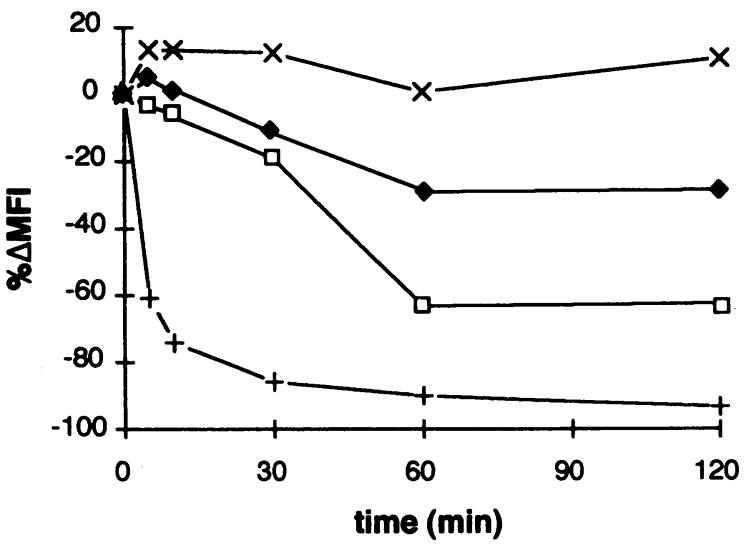

Figure 3. Dose response and time course of the effect of NSAIDs on L-selectin neutrophil expression. $(A)$ Dose response of the L-selectin downregulation induced by NSAIDs on normal neutrophils. Cells were cultured for $1 \mathrm{~h}$ in the presence of different concentrations of various NSAIDs. The dots indicate the average of three different experiments and the error bars indicate the ranges $-\square-$, indomethacin; -+diclofenac; $-\times-$, piroxicam; and $-\diamond-$, aspirin. $(B)$ Kinetics of the effect NSAIDs on normal neutrophils. Cells were cultured in the presence of $40 \mu \mathrm{g} / \mathrm{ml}$ of indomethacin, diclofenac, and piroxicam and $0.5 \mathrm{mg} / \mathrm{ml}$ aspirin until $120 \mathrm{~min}$. The percentage of variation of the $\mathrm{L}$ selectin expression ( $\% \Delta \mathrm{MFI})$ was related to the expression by cultured cells in medium in each time.

containing granules (30). As control, cell stimulation with the phorbol ester PMA induced a high secretion of gelatinase as well as the partial release of lysozyme. No secretion of $N$ acetyl- $\beta$-glucosaminidase (a marker for azurophilic granules), even under the highest stimulatory condition, was observed ( Table I).

These results suggest that neutrophil activation is not involved in the mechanism of regulation of $\mathrm{L}$-selectin expression by indomethacin, ketoprofen, and aspirin. However, it is possible that the downregulation of L-selectin induced by diclofenac is, at least in part, mediated by a cell activation-dependent mechanism.
In vivo effect of indomethacin on neutrophil L-selectin expression. To ascertain the relevance of the above described observations, in vivo experimentation with human healthy volunteers was carried out. A preliminary kinetics study with two individuals taking physiological amounts of indomethacin (25 $\mathrm{mg}$, three times a day, during $4 \mathrm{~d}$ ), showed a significant neutrophil L-selectin downregulation beginning at $24 \mathrm{~h}$, that was maintained during treatment (data not shown). Therefore, we decided to undertake the study of the neutrophil expression of Lselectin, CD11b, and CD11a in seven different volunteers 24 , and $48 \mathrm{~h}$ after starting the administration protocol of indomethacin. The results obtained are shown in Fig. 6. A mean decrease of $38 \%$ (95\% CI $21 \%, 55 \%)$ of L-selectin expression level was observed after $24 \mathrm{~h}$, that was slightly lower by $48 \mathrm{~h}$. In contrast, CD11b and CD11a neutrophil expression did not significantly change.

These results confirm in vivo, the in vitro observations of L-selectin downregulation with no significant change of CD11b after neutrophil exposure to indomethacin. Furthermore, they also indicate that physiological amounts of this NSAID caused a noticeable loss of neutrophil L-selectin.

Treatment of human neutrophils with NSAIDs causes shedding of L-selectin. L-selectin is constitutively expressed at the cell surface of neutrophils and it is rapidly shed after either cell activation (20-22) or activation-independent chemical crosslinking (38). Therefore, we investigated whether the NSAIDs exert their blocking effects on neutrophil-endothelial cell adhesion by the removal and shedding of L-selectin.

To this end, neutrophils were treated with different NSAIDs and then immunoprecipitation of L-selectin from both cell lysates and cell-free supernatants was performed. L-selectin was immunoprecipitated from the cell-free supernatant from neutrophils that have been treated with either indomethacin, diclofenac, or aspirin, but not from their corresponding cell lysates (Fig. $7 A$ ). In contrast, no $\mathrm{CD} 11 \mathrm{~b}$ or $\mathrm{CD} 31$ antigens were immunoprecipitated from cell-free supernatants of NSAIDstreated neutrophils (Fig. 7, $B$ and $C$ ). Furthermore, the amounts of sL-selectin detected with an ELISA in the cell-free supernatants of neutrophils treated with indomethacin and diclofenac were similar to that observed in TNF- $\alpha$-activated cells, and they varied between 1.6 to $2.2 \mathrm{ng} / \mathrm{ml}$ per $10^{6}$ cells (Fig. 8). In contrast, lower amounts of sL-selectin $\left(0.5 \mathrm{ng} / \mathrm{ml}\right.$ per $10^{6}$ cells $)$ were found in the supernatant fluid of neutrophils incubated with piroxicam or medium (Fig. 8). These data demonstrate that some NSAIDs induce a selective and activation-independent shedding of L-selectin in neutrophils.

\section{Discussion}

The endothelium plays an essential role in inflammation, providing the key signals for leukocyte migration to extravascular tissues. In normal conditions, the circulating leukocytes have continuous random contacts with endothelial cells, but no firm interactions occur. When a tissue is injured, the endothelial cells are activated by extravascular stimuli inducing the expression of a wide array of cell surface adhesion molecules. These molecules mediate a close receptor-counterreceptor interaction with circulating leukocytes, allowing the adhesion and the extravasation of leukocytes through vascular endothelium at sites of inflammation. The initial interaction with endothelium facilitates the rolling and arrest of circulating leukocytes on the endothelium surface. One of the leukocyte molecules involved in this 


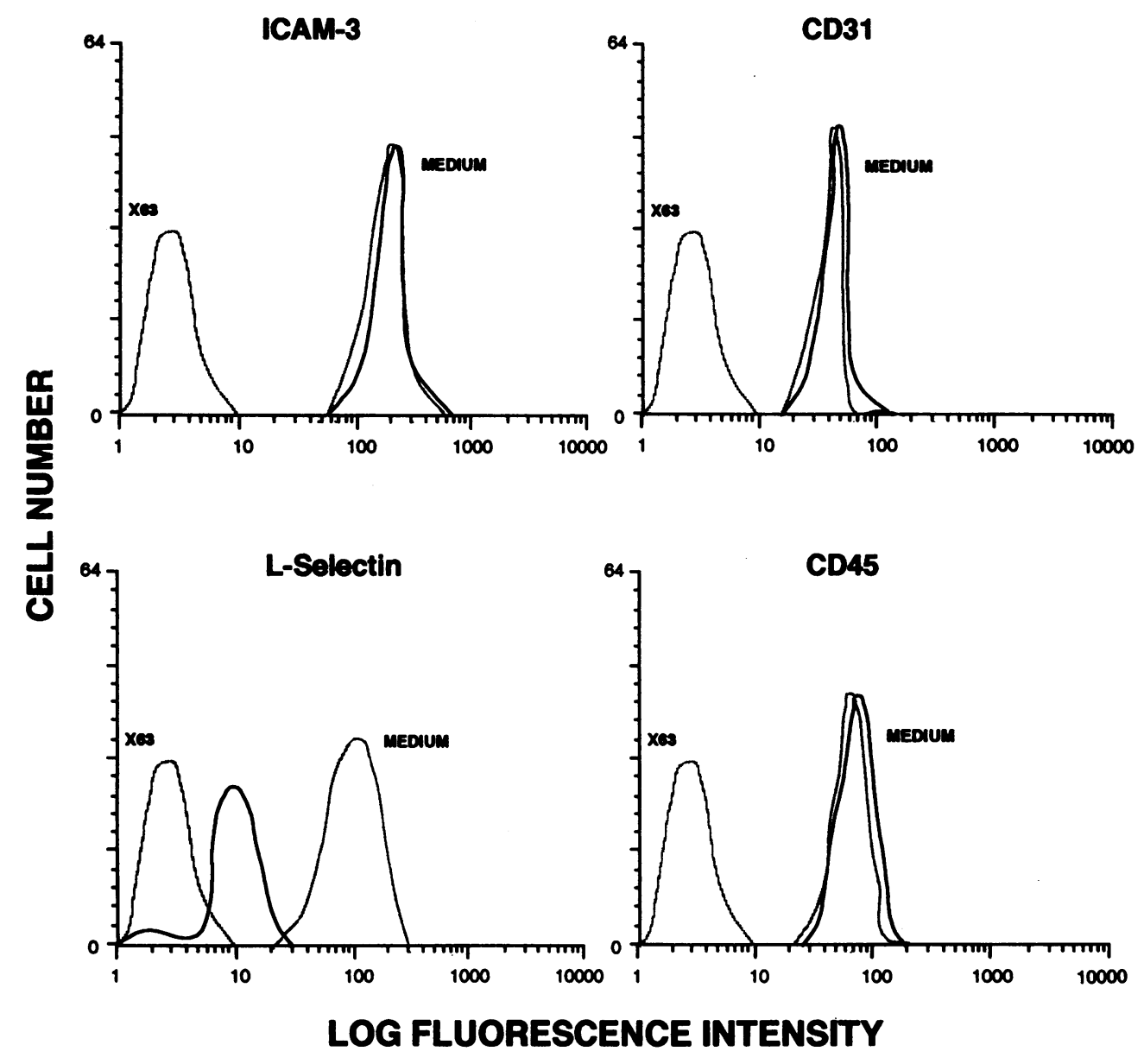

Figure 4. Effect of indomethacin on neutrophil surface expression of ICAM-3, CD31, and CD45. Neutrophils were incubated for 15 $\min$ at $37^{\circ} \mathrm{C}$ in the presence of 0.2 $\mathrm{mg} / \mathrm{ml}$ indomethacin (solid line). In each histogram is displayed the basal expression of the cell surface protein (medium) and the negative control of immunostaining ( $\mathrm{P} 3 \mathrm{X63})$. initial interaction is the L-selectin, a member of the selectin family which recognizes carbohydrates expressed by the activated endothelium $(34,39-42)$. Nowadays, research teams have undertaken strategies towards treating inflammation by blocking the selectin-mediated functions (43-45). In this therapeutic approach, it is assumed that if the initial L-selectinmediated leukocyte rolling could be blocked, the following events involved in the leukocyte migration to the tissue would not occur and the inflammatory response would be alleviated.

The aim of this study was to search for drugs with the capability of blocking the binding of neutrophils to endothelial cells and to determine their mechanisms of action. To this end, a neutrophil-HUVEC attachment assay was used to study the first step of neutrophil migration. To simulate the blood flow, the experiments were performed under nonstatic conditions (36). In these assays, the binding of neutrophils to activated HUVEC was mediated by the L-selectin as it occurs during both in vitro and in vivo rolling at physiologic cell flow rates (4-6). Initially, we studied the effect on neutrophils of drugs with antiinflammatory properties such as glucocorticoids and NSAIDs. The preincubation of neutrophils with different NSAIDs produced a dramatic abrogation of the neutrophil attachment to activated HUVEC. In contrast, dexamethasone showed no effect pointing out that nonsteroidal drugs had a different antiinflammatory mechanism of action. This inhibitory effect on neutrophil adhesiveness is not common to all NSAIDs; piroxicam, an enolic acid-derived NSAID, did not show any inhibitory effect on the L-selectin-mediated neutrophil-HUVEC attachment assay.
Preliminary evidence indicates that piroxicam interferes with the process of neutrophil activation and degranulation, induced by stimuli like TNF- $\alpha$ or the chemoattractant peptide FMLP (Díaz-González, unpublished observations). Although the major mechanism of action of NSAIDs is well established to be ciclooxigenase inhibition and interference with synthesis of prostaglandins (27), our results point out differences in the effects and mode of action among various NSAIDs, in accordance with previous reported work (46). In this regard, it has recently been described that certain NSAIDs, as sodium salicylate and aspirin, inhibit NF-KB-dependent transcription activity (47). A chemical structure common to aspirin, indomethacin, diclofenac, and ketoprofen, but absent in piroxicam, might be responsible for the L-selectin shedding in neutrophils; this datum might be important for the future development of new antiinflammatory drugs that interfere with L-selectin-mediated function.

The relevant role of L-selectin in the nonstatic binding assay used by us, suggested that NSAIDs could affect the neutrophil L-selectin expression. In this regard, we have shown herein that those drugs which inhibit the neutrophil-HUVEC attachment, also downregulate the L-selectin cell surface expression in a dose- and time-dependent manner. However, neither piroxicam nor dexamethasone modified the basal expression of this selectin in neutrophils. Activation of neutrophils uniformly results in downregulation of L-selectin expression (20-22) as well as in upregulation of both $\mathrm{CD} 1 \mathrm{~b} / \mathrm{CD} 18$ and $\mathrm{CD} 45$ expression $(22,30,37)$. Nevertheless, the basal expression of CD11b and 
A :Henduldull

B
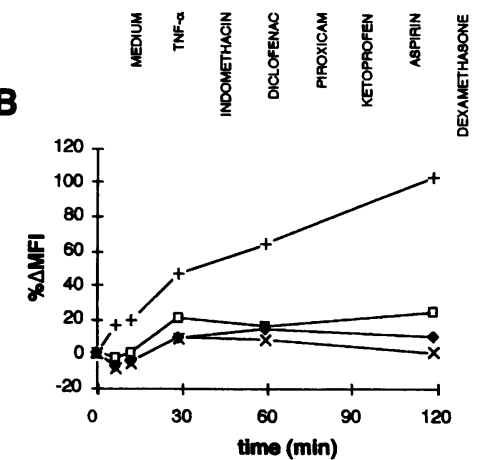

C

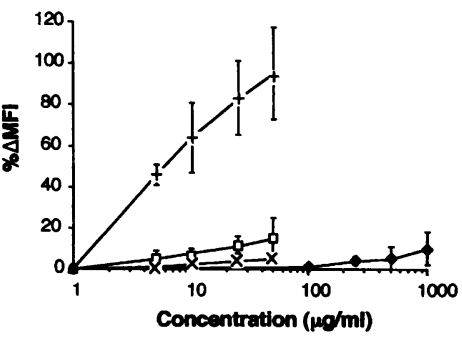

Figure 5. Effect of NSAIDs on neutrophil CD11b cell surface expression. $(A)$ Linear mean fluorescence intensity of CD11a ( $\square)$, CD11b (ם), and L-selectin (匹) after incubation with $0.2 \mathrm{mg} / \mathrm{ml}$ indomethacin, diclofenac, and piroxicam, $2 \mathrm{mg} / \mathrm{ml}$ ketoprofen, $1 \mathrm{mg} / \mathrm{ml}$ aspirin and $0.2 \mathrm{mg} / \mathrm{ml}$ dexamethasone for 15 $\min$ at $37^{\circ} \mathrm{C}$. A downregulatory effect of indomethacin, diclofenac, ketoprofen, and aspirin on L-selectin expression is shown. Only diclofenac induced a simultaneous upregulation of CD11b. (B) Kinetics of the effect of NSAIDs on the surface expression of CD11b. The drugs were used at the same doses as indicated in $(A)$.

- - , indomethacin, -+- , diclofenac; $-x-$, piroxicam; and $-\diamond-$, aspirin. $(C)$ Dose response of $\mathrm{CD} 11 \mathrm{~b}$ expression under same

experimental conditions as in Fig. $3 \mathrm{~A}$. The dots indicate the mean and the error bars indicate the ranges.

CD45 was unaffected by most of the drugs tested, suggesting that neutrophils are not activated by NSAIDs, and that the downregulation of L-selectin is mediated by an activation-independent mechanism. This is further supported by the lack of neutrophil degranulatory activity of NSAIDs as determined by

Table I. Granule Marker Release in Human Neutrophils by Different NSAIDs

\begin{tabular}{llrr}
\hline & \multicolumn{3}{c}{ Enzyme release } \\
\cline { 2 - 4 } & Gelatinase & Lysozyme & NABGase \\
\hline Control & $21.3 \pm 2.1$ & $5.9 \pm 1.7$ & $2.5 \pm 0.5$ \\
PMA & $63.7 \pm 10.7$ & $33.6 \pm 2.9$ & $3.1 \pm 0.6$ \\
TNF- $\alpha$ & $53.8 \pm 8.8$ & $8.9 \pm 1.6$ & $3.0 \pm 0.2$ \\
Diclofenac & $38.9 \pm 8.6$ & $8.1 \pm 2.8$ & $2.5 \pm 0.3$ \\
Piroxicam & $16.0 \pm 5.4$ & $1.8 \pm 0.9$ & $2.9 \pm 0.6$ \\
Ketoprofen & $21.6 \pm 1.3$ & $4.1 \pm 1.9$ & $2.2 \pm 0.2$ \\
Aspirin & $16.1 \pm 2.2$ & $5.0 \pm 2.1$ & $2.4 \pm 0.4$ \\
Indometacin & $23.8 \pm 3.3$ & $6.1 \pm 2.0$ & $3.3 \pm 0.8$ \\
\end{tabular}

Data are shown as percentage of total cellular enzyme activity released to the extracellular medium. Total cell enzyme was measured in resting cells disrupted by treatment with $0.1 \%$ Triton X-100 and/or by thawing/ freezing. Values are shown as mean $\pm \mathrm{SE}$ of three independent determinations. $N \mathrm{~A} \beta \mathrm{Gase}, N$-acetyl- $\beta$-glucosaminidase.

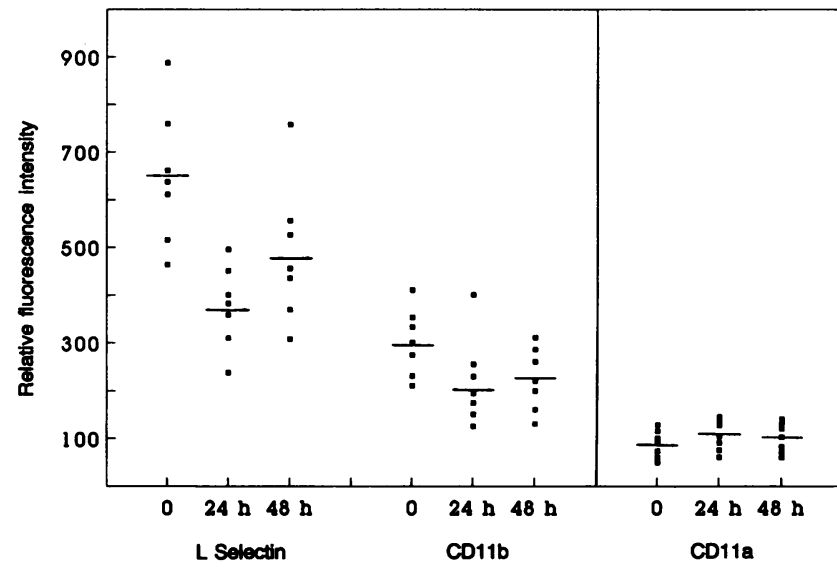

Figure 6. Expression of L-selectin and CD11b adhesion molecules on neutrophils from healthy volunteers during administration of indomethacin. L-selectin neutrophil levels decreased significantly at $24 \mathrm{~h}(P$ $<0.01)$, and $48 \mathrm{~h}(P<0.001)$ after indomethacin treatment; CD11b expression had no significant variation. Levels of CD11a expression are presented as absolute immunofluorescence intensity, showing the absence of changes during treatment.

granule enzyme release. Only diclofenac induced a significant increase of the expression of both CD11b and CD45 glycoproteins, as well as a partial neutrophil degranulation suggesting that this drug is capable, at least in part, to downregulate Lselectin expression through a mechanism that involves neutrophil activation. Accordingly, it has been reported that crosslinking of the L-selectin is also an activation-independent mechanism of downregulation of this molecule (38). In addition, high levels of soluble L-selectin have been found in plasma from normal subjects (25), suggesting that this soluble L-selectin is released from leukocytes through a mechanism in which cell activation is not involved.

It has been reported that the loss of L-selectin in activated neutrophils takes place through a proteolytic shedding of the molecule and that none of the known protease inhibitors inhibit the shedding of L-selectin $(14,20,22,25)$. We have demonstrated that the loss of L-selectin induced by NSAIDs is also due to the shedding of the molecule from the cell surface, as confirmed by both immunoprecipitation and quantitative estimation of a soluble form of this molecule in cell-free supernatants of neutrophils treated with those drugs. It is tempting to speculate that a selective activation of a specific protease might account for this phenomenon. However, the mechanism of this NSAIDs-mediated L-selectin activation-independent shedding remains to be clarified. Although an inherent proteolytic activity of NSAIDs themselves on L-selectin cannot be completely ruled out, the observation that this phenomenon does not occur at $4^{\circ} \mathrm{C}$ supports the presence of an inducible cellular protease.

The concentrations of different NSAIDs required in our in vitro studies for the L-selectin shedding from neutrophil surface appear to be higher than those described to exert its antiinflammatory effects in vivo (48). Interestingly enough, when healthy donors were treated with physiological doses of indomethacin, a significant loss of L-selectin neutrophil expression was detected, with no change in CD11a or CD11b expression. This decrement of neutrophil L-selectin in vivo is remarkable taking into account that it is observed in the cell population of blood neutrophils, that is subjected to a rapid and continuous renewal. On 


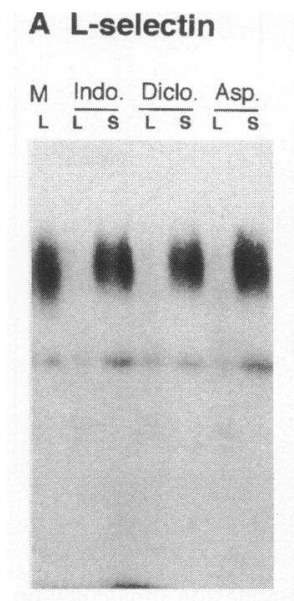

B CD11b

\section{CD31}

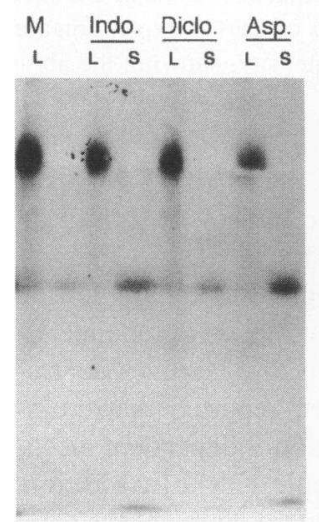

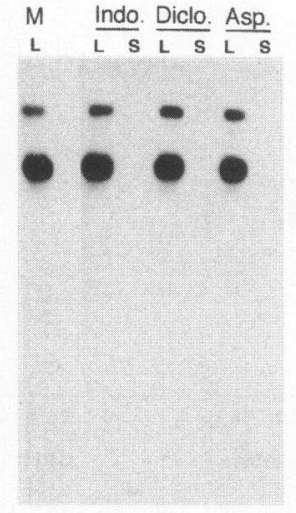

D Negative Control

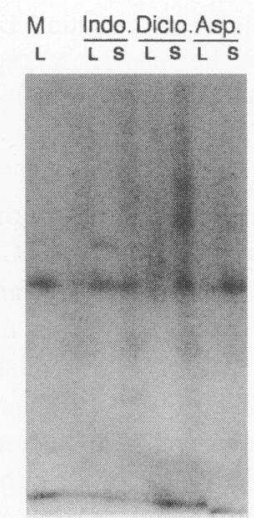

Figure 7. Immunoprecipitation of L-selectin, CD11b, and CD31 from cell lysates $(L)$ and cell-free supernatants $(S)$. Untreated (Medium) and NSAIDs-treated neutrophils, with the doses and time used in the neutrophil-endothelial attachment assay (see Methods) were immunoprecipitated with the following mAb: anti-LAM-1 Leu-8, anti-CD11b Bear-1, anti-CD31 TP1/15, and P3 X63 as negative control. Indo, indomethacin; Diclo, diclofenac; Asp, aspirin.

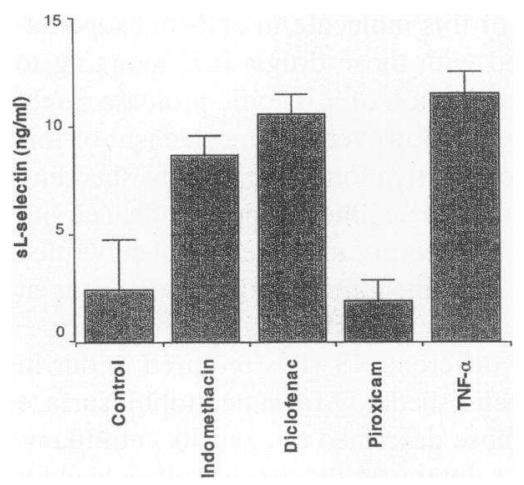

Figure 8. Quantification of neutrophil-shed L-selectin induced by NSAIDs. Neutrophils ( 5 $\left.\times 10^{6}\right)$ were incubated in medium alone (control) or in the presence of indomethacin $(0.2 \mathrm{mg} /$ $\mathrm{ml})$, diclofenac $(0.2 \mathrm{mg} /$ $\mathrm{ml})$, piroxicam $(0.2 \mathrm{mg} /$ $\mathrm{ml})$, and TNF- $\alpha(20 \mathrm{ng} /$ $\mathrm{ml}$ ) for $15 \mathrm{~min}$ at $37^{\circ} \mathrm{C}$. Culture medium samples were centrifuged, and supernatant fluids were

tested for sL-selectin by a specific ELISA. The concentration of sLselectin was calculated by comparing the OD with those obtained with recombinant sL-selectin standards, using a linear regression analysis. Values represent the mean $(\mathrm{ng} / \mathrm{ml}) \pm$ SE obtained in duplicate determinations for each sample. The results are representative of two experiments.

the other hand, indomethacin does not appear to activate neutrophils in vivo as determined by its failure to upregulate CD11b expression. However, it is difficult to establish a strict correlation between our in vitro observations and in vivo behavior of these types of drugs which is depending not only on plasma levels, but also on different factors as preferential tissue accumulation, plasma half-lives, hepatic biotransformation, and enterohepatic recycling of NSAIDs. On the other hand, all these pharmacologic parameters are different for the various NSAIDs groups (46). Nevertheless, it is conceivable that the action of these drugs on L-selectin neutrophil surface expression might account, at least in part, for antiinflammatory activity of NSAIDs.

In summary, we have shown that some NSAIDs inhibit neutrophil attachment to HUVEC in vitro through a rapid Lselectin cell shedding. These results suggest a specific mechanism of regulation of neutrophil adhesion functions by NSAIDs, which open a door for the development of new antiinflammatory drugs based on a selective L-selectin shedding activity. Therefore, the measurement of neutrophil L-selectin cell surface expression, could be a rapid and reproducible primary assay in the search of drugs with antiinflammatory activity.

\section{Acknowledgments}

The authors appreciate the critical reading of Drs. González-Amaro, A. A. Postigo, A. L. Corbí, and M. O. de Landázuri, and the technical assistance of M. A. Ursa and E. Esguevillas. We also thank Dr. A. Laffón for his continuous support.

This work was supported by grants, PB 92-0318 from Dirección General de Investigación, Ciencia y Tecnología, CAM 028/92 from Comunidad Autónoma de Madrid, and FIS 95/0212 from Fondo de Investigaciones Sanitarias to F. Sánchez-Madrid.

\section{References}

1. Butcher, E. C. 1991. Leukocyte endothelial cell migration: three (or more) steps to specificity and diversity. Cell. 67:1033-1036.

2. Shimizu, Y., W. Newman, Y. Tanaka, and S. Shaw. 1992. Lymphocyte interactions with endothelial cells. Immunol. Today. 13:106-112.

3. Springer, T. A. 1994. Traffic signals for lymphocyte recirculation and leukocyte emigration: the multistep paradigm. Cell. 76:301-314.

4. Ley, K., P. Gaehtgens, C. Fennie, M. S. Singer, L. A. Lasky, and S. D. Rosen. 1991. Lectin-like cell adhesion molecule 1 mediate leukocyte rolling in mesenteric venules in vivo. Blood. 77:2553-2555.

5. von Andrian, U. H. J. D. Chambers, L. M. McEvoy, R. F. Bargatze, K. E Arfors, and E. C. Butcher. 1991. Two-step model of leukocyte-endothelial cell interaction in inflammation: distinct roles of LECAM-1 and the leukocyte $\beta 2$ integrins in vivo. Proc. Natl. Acad. Sci. USA. 88:7538-7542.

6. Lawrence, M. B., and T. A. Springer. 1991. Leukocytes roll on a selectin at physiologic flow rates: distinction from and prerequisite for adhesion through integrins. Cell. 65:859-873.

7. Zimmerman, G. A., S. M. Prescott, and T. M. McIntyre. 1992. Endothelia cell interactions with granulocytes: tethering and signaling molecules. Immunol. Today. 13:93-100.

8. McEver, R. P. 1992. Leukocyte-endothelial cell interactions. Curr. Opin. Cell Biol. 4:840-849.

9. Lasky, L. A. 1992. Selectins: interpreters of cell-specific carbohydrate information during inflammation. Science (Wash. DC). 258:964-969.

10. Stenberg, P. E., R. P. McEver, M. A. Shuman, Y. V. Jacques, and D. F. Bainton. 1985. A platelet alpha-granule membrane protein (GMP-140) is expressed on the plasma membrane after activation. J. Cell Biol. 101:880-886.

11. McEver, R. P., J. H. Beckstead, K. L. Moore, L. Marshall-Carlson, and D. F. Bainton. 1989. GMP-140, a platelet $\alpha$-granule membrane protein, is also synthesized by vascular endothelial cells and is localized in Weibel-Palade bodies. J. Clin. Invest. 84:92-99.

12. Hsu-Lin, S. C., C. L. Berman, B. C. Furie, D. August, and B. Furie. 1984. A platelet membrane protein expressed during platelet activation and secretion. Studies using a monoclonal antibody specific for thrombin-activated platelets. $J$. Biol. Chem. 259:9121-9126. 
13. Bevilacqua, M. P. 1993. Endothelial-leukocyte adhesion molecules. Annu. Rev. Immunol. 11:767-804.

14. Griffin, J. D., O. Spertini, T. J. Ernst, M. P. Belvin, H. B. Levine, Y. Kanakura, and T. F. Tedder. 1990. GM-CSF and other cytokines regulate surface expression of the leukocyte adhesion molecule-1 on human neutrophils, monocytes and their precursors. J. Immunol. 145:576-584.

15. Tedder, T. F., T. Matsuyama, D. M. Rothstein, S. F. Schlossman, and C. Morimoto. 1990. Human antigen-specific memory $\mathrm{T}$ cells express the homing receptor necessary for lymphocyte recirculation. Eur. J. Immunol. 20:1351-1355.

16. Lasky, L. A., M. S. Singer, D. Dowbenko, Y. Imai, W. J. Henzel, C. Grinley, C. Fennie, N. Gillet, S. R. Watson, and S. D. Rosen. 1992. An endothelial ligand for L-selectin is a novel mucin-like molecule. Cell. 69:927-938.

17. Baumhueter, S., M. S. Singer, W. J. Henzel, S. Hemmerich, M. Renz, S. D. Rosen, and L. A. Lasky. 1993. Binding of L-selectin to the vascular sialomucin CD34. Science (Wash. DC). 262:436-438.

18. Berg, E. L., L. M. McEvoy, C. Berlin, R. F. Bargatze, and E. C. Butcher. 1993. L-selectin-mediate lymphocyte rolling on MadCAM-1. Nature (Lond.). 366:695-698.

19. Picker, L. J., R. A. Warnock, A. R. Burns, C. M. Doerschuck, E. L. Berg, and E. C. Butcher. 1991. The neutrophil selectin LECAM-1 presents carbohydrate ligands to the vascular selectins ELAM-1 and GMP-140. Cell. 66:921-933.

20. Kishimoto, T. K., M. A. Jutila, E. L. Berg, and E. C. Butcher. 1989. Neutrophil Mac-1 and MEL-14 adhesion proteins inversely regulated by chemotactic factors. Science (Wash. DC). 245:1238-1241.

21. Berg, M., and S. P. James. 1990. Human neutrophils release the Leu-8 lymph node homing receptor during cell activation. Blood. 76:2381-2388.

22. Campanero, M. R., R. Pulido, J. L. Alonso, J. P. Pivel, F. X. PimentelMuiños, M. Fresno, and F. Sánchez-Madrid. 1991. Down-regulation by tumor necrosis factor alpha of neutrophil cell surface expression of the sialophorin CD43 and the hyaluronate receptor CD44 through a proteolytic mechanism. Eur. J. Immunol. 21:3045-3048.

23. Jutila, M. A., L. Rott, E. L. Berg, and E. C. Butcher. 1989. Function and regulation of the neutrophil MEL-14 antigen in vivo: comparison with LFA-1 and MAC-1. J. Immunol. 143:3318-3324.

24. Humbria, A., F. Díaz-González, M. R. Campanero, A. G. Arroyo, A Laffón, R. González-Amaro, and F. Sánchez-Madrid. 1994. Expression of Lselectin, CD43 and CD44 in synovial fluid neutrophils from inflammatory joint disease. Evidence for a soluble form of L-selectin in synovial fluid. Arthritis Rheum. 37:342-348.

25. Schleiffenbaum, B., O. Spertini, and T. F. Tedder. 1992. Soluble L-selectin is present in human plasma at high levels and retains functional activity. $J$. Cell Biol. 119:229-238.

26. Langman, M. J. S. 1988. Ulcer complications and nonsteroidal anti-inflammatory drugs. Am. J. Med. 84(Suppl. 2):15-19.

27. Vane, J. R. 1971. Inhibition of prostaglandin synthesis as a mechanism of action for the aspirin-like drugs. Nature (Lond.). 231:232-235.

28. Abramson, S. B., and G. Weissman. 1989. The mechanism of action of nonsteroidal antiinflammatory drugs. Arthritis Rheum. 32:1-9.

29. Forrest, M., and P. M. Brooks. 1988. Mechanism of action of non-steroidal anti-rheumatic drugs. Clin. Rheumatol. 2:275-294.

30. Lacal, P., R. Pulido, F. Sánchez-Madrid, and F. Mollinedo. 1988. Intracellular location of T200 and Mol glycoproteins in human neutrophils. J. Biol. Chem. 263:9946-9951.

31. Campanero, M. R., M. A. del Pozo, A. G. Arroyo, P. Sánchez-Mateos, T. Hernández-Caselles, A. Craig, R. Pulido, and F. Sánchez-Madrid. 1993. ICAM-
3 interacts with LFA-1 and regulates the LFA-1/ICAM-1 cell adhesion pathway. J. Cell. Biol. 123:1007-1016.

32. Spertini, O., G. S. Kansas, K. A. Reimann, C. R. Mackay, and T. Tedder 1991. Function and evolutionary conservation of distinct epitopes on the leukocyte adhesion molecule-1 (TQ-1, Leu-8) that regulate leukocyte migration. J. Immunol. 147:942-949.

33. Sánchez-Madrid, F., J. Nagy, E. Robbins, P. Simon, and T. A. Springer 1983. A human leukocyte differentiation antigen family with distinct $\alpha$-subunits and a common $\beta$ subunit: the lymphocyte function-associated antigen (LFA-1) the C3bi complement receptor (OKM1, Mac-1), and the p150,95 molecule. $J$. Exp. Med. 158:1785-1803.

34. Spertini, O., F. W. Luscinskas, J. M. Munro, G. S. Kansas, J. D. Griffin M. A. Gimbrone, and T. F. Tedder. 1991. Leukocyte adhesion molecule (LAM-1, L-selectin) interacts with an inducible endothelial cell ligand to support leukocyte adhesion and transmigration. J. Immunol. 147:2565-2573.

35. Mollinedo, F., F. S. Manara, and D. L. Schneider. 1986. Acidification activity of human neutrophils. Tertiary granules as a site of ATP-dependent acidification. J. Biol. Chem. 261:1077-1082.

36. Spertini, O., F. W. Luscinskas, M. A. Gimbrone, Jr., and T. F. Tedder 1992. Monocyte attachment to activated human vascular endothelium in vitro is mediated by leukocyte adhesion molecule-1 (L-selectin) under non-static conditions. J. Exp. Med. 175:1789-1792.

37. Miller, L. J., D. F. Bainton, N. Borregaard, and T. A. Springer. 1987 Stimulated mobilization of monocyte Mac-1 and p150,95 adhesion proteins from an intracellular vesicular compartment to the cell surface. J. Clin. Invest. 80:535544.

38. Palencada, A., B. Walcheck, D. K. Bishop, and M. A. Jutila. 1992. Rapid activation-independent shedding of leukocyte L-selectin induced by cross-linking of the surface antigen. Eur. J. Immunol. 22:1279-1286.

39. Imai, Y., M. S. Singer, C. Fennie, L. A. Lasky, and S. D. Rosen. 1991. Identification of a carbohydrate-based endothelial ligand for a lymphocyte homing receptor. J. Cell. Biol. 113:1213-1221.

40. True, D. D., M. S. Singer, L. A. Lasky, and S. D. Rosen. 1990. Requirement for sialic acid on the endothelial ligand of a lymphocyte homing receptor. J. Cell. Biol. 111:2757-2764.

41. Yednock, T. A., L. M. Stoolman, and S. D. Rosen. 1987. Phosphomannosyl-derivatized beads detected a receptor involved in lymphocyte homing. J. Cell. Biol. 104:713-723.

42. Spertini, O., G. S. Kansas, J. M. Munro, J. D. Griffin, and T. F. Tedder 1991. Regulation of leukocyte migration by activation of the leukocyte adhesion molecule-1 (LAM-1) selectin. Nature (Lond.). 349:691-694.

43. Watson, S. R., C. Fennie, and L. A. Lasky. 1991. Neutrophil influx into an inflammatory site inhibited by a soluble homing receptor-IgG chimaera. Nature (Lond.). 349:164-167.

44. Mulligan, M. S., J. C. Paulson, S. De Frees, Z. L. Zheng, J. B. Lowe, and P. A. Ward. 1993. Protective effects of oligosaccharides in P-selectin-dependent lung injury. Nature (Lond.). 364:149-151.

45. Travis, J. 1993. Biotech gets a grip on cell adhesion. Science (Wash. DC). 260:906-908.

46. Brooks, P. M., and R. O. Day. 1991. Nonsteroidal antiinflammatory drugs. Differences and similarities. N. Engl. J. Med. 324:1716-1725.

47. Kopp, E., and S. Ghosh. 1994. Inhibition of NF-KB by sodium salicylate and aspirin. Science (Wash. DC). 265:956-958.

48. Flower, R. J., S. Moncada, and J. R. Vane. 1980. Antipyretic, analgesic, and antiinflammatory agents. Drugs employed in the treatment of gout. In The Pharmacological Basis of Therapeutics. A. G. Goodman and L. H. Gilman, editors. MacMillan Publishing Co., New York. 682-698. 